\title{
Transmembrane protein 66 attenuates neointimal hyperplasia after carotid artery injury by SOCE inactivation
}

\author{
JIONG YANG, SHUANG LI, QIANG WANG and DACHUN YANG \\ Department of Cardiology, The General Hospital of Western Theater Command, Chengdu, Sichuan 610083, P.R. China
}

Received November 10, 2018; Accepted May 10, 2019

DOI: $10.3892 / \mathrm{mmr} .2019 .10328$

\begin{abstract}
Neointimal hyperplasia could be one of the most important complications after balloon angioplasty. Since calcium signaling has several physiologic effects on the regulation of the proliferation and migration of vascular smooth muscle cells (VSMCs), it was hypothesized that transmembrane protein 66 (TMEM66), a store operated calcium entry (SOCE)-associated regulatory factor, possesses vascular protection against balloon injury. The rat balloon-induced carotid artery injury model was performed. Histological analysis was used to check neointimal hyperplasia. TMEM66 expression was measured by PCR and immunoblotting. The results revealed that TMEM66 was expressed in the medial and neointimal layers of the injured artery, and the expression of TMEM66 was markedly decreased. TMEM66 overexpression attenuated neointimal hyperplasia via VSMC proliferation/migration inhibition, and restored expression of VSMC phenotypic markers. Moreover, TMEM66 overexpression reduced the increased expression of Stim1 and Orail and PDGF-BB treatment-enhanced $\left[\mathrm{Ca}^{2+}\right]_{\mathrm{i}}$. In conclusion, TMEM66 protects against balloon injury-induced neointimal hyperplasia, and may be a pharmacological target for the treatment of restenosis.
\end{abstract}

\section{Introduction}

Due to the widespread use of percutaneous coronary intervention (PCI) in clinical practice, balloon angioplasty is one of the most common medical procedures in the world (1). Although balloon angioplasty is effective in the treatment of coronary stenosis, complications have restricted its use. Previous studies have indicated a high rate of restenosis in patients undergoing

Correspondence to: Dr Dachun Yang or Dr Qiang Wang, Department of Cardiology, The General Hospital of Western Theater Command, 270 Rongdu Ave, Jinniu, Chengdu, Sichuan 610083, P.R. China

E-mail: yangdc71@126.com

E-mail: qwang_86@163.com

Key words: transmembrane protein 66, neointimal hyperplasia, store operated calcium entry successful coronary angioplasty, because of constrictive remodeling and neointimal hyperplasia (2). Neointimal hyperplasia causing vessel renarrowing is one of the key limitations for long-term outcomes. However, the mechanisms of balloon injury-induced neointimal hyperplasia are complex and remain to a large extent unexplored.

Through largely unknown mechanisms, calcium signaling plays an important role in neointimal hyperplasia $(3,4)$. Store operated calcium entry (SOCE) represents a key mechanism, by which cells convey $\mathrm{Ca}^{2+}$ signals and maintain $\mathrm{Ca}^{2+}$ homeostasis (5), and is critical for the proliferation and migration of vascular smooth muscle cells (VSMCs) in neointima. Previous studies found that transmembrane protein 66 (TMEM66), also named hereafter as SARAF (for SOCE-associated regulatory factor), plays a key role in shaping cytosolic $\mathrm{Ca}^{2+}$ signals and determining the content of the major intracellular $\mathrm{Ca}^{2+}$ stores, as a negative regulator of SOCE (6). In addition, TMEM66 is a protein with a putative transmembrane domain, a N-terminal region that is required for the activation of the protein, and a C-terminal domain that has been shown to be involved in the interaction with the C-terminal inhibitory domain of Stim1, downstream of the Stim1 and Orai1 activation region (7). Thus, we speculated that TMEM66 may be critical for the proliferation and migration of VSMCs in neointima.

\section{Materials and methods}

Rat balloon-induced carotid artery injury model. A total of 16 male Sprague-Dawley (SD) rats, 8 month old and weighing 310 to $380 \mathrm{~g}$, were obtained from the Experimental Animal Centre of The General Hospital of Western Theater Command at Chengdu, China. Rats were housed in a room with a 12 light-dark cycle at $23^{\circ} \mathrm{C}$ and given free access to standard rodent food and tap water. Rats randomized to the sham-operated group, balloon injury group and TMEM66-overexpression group. Balloon denudation was performed as previously described, with a 2-French catheter in the left common carotid artery $(8,9)$. After balloon injury, a $100 \mu$ l solution of lenti-TMEM66-GFP $\left(10^{8} \mathrm{IU}\right.$ per rat) or PBS were infused into the injured artery segment and incubated for $15 \mathrm{~min}$. The efficiency of transfection was identified by fluorescence microscopy (Fig. S1). After 4 week balloon injury and lentiviral infection, the rats were euthanized using an overdose of sodium pentobarbital. The vessel tissues were harvested for the subsequent experiments. This study was approved by the Research Council and Animal Care and 
Use Committee of The General Hospital of Western Theater Command. All experiments conformed to the guidelines of the American Association for the Accreditation of Laboratory Animal Care and conformed to the guidelines of the ethical use of animals, and all efforts were made to minimize animal suffering and to reduce the number of animals used.

Immunoblotting. Carotid artery tissues were lysed in lysis buffer (Beyotime Institute of Biotechnology) and centrifuged at $15,000 \times \mathrm{g}$. The homogenates were separated by SDS-polyacrylamide gel (4\% stacking gel with an $8 \%$ separating gel) and transferred to nitrocellulose filter membranes. The transblots were probed with the rabbit anti-TMEM66 antibody (1:500; cat. no. ab80890; Abcam), rabbit anti- $\alpha$-SMA antibody (1:500; cat. no. ab32575; Abcam) and rabbit anti-calponin antibody (1:500; cat. no. ab46794; Abcam) at $4^{\circ} \mathrm{C}$ overnight, after washing with TBST and blocking with $1 \% \mathrm{BSA}$. The membranes were then washed and incubated with goat anti-rabbit-IgG (1:4,000; cat. no. BA1039; Boster Biological Technology) conjugated to horseradish peroxidase at room temperature for $1 \mathrm{~h}$, and the bands were visualized with enhanced chemiluminescence (EMD Millipore). The amount of protein transferred onto the membranes was verified by immunoblotting for GAPDH (rabbit anti-GAPDH; 1:1,000; cat. no. ab181602; Abcam).

RNA extraction and PCR. RNA from the carotid artery was extracted using Trizol (Thermo Fisher Scientific, Inc.), synthesized to cDNA and served as a template for amplification of TMEM66 using an RNA reverse transcriptase kit (Takara Biotechnology Co., Ltd.) under the following conditions: $37^{\circ} \mathrm{C}$ for $15 \mathrm{~min}$ and $85^{\circ} \mathrm{C}$ for $5 \mathrm{sec}$. The cDNA was then stored at $4^{\circ} \mathrm{C}$. Primer information is described in a previous study (10). Amplification was performed using quantitative PCR (qPCR) using a SYBR Green Premix (SYBR Real-Time PCR Kit; Takara Biotechnology Co., Ltd.), according to the manufacturer's instructions using the following conditions: $50^{\circ} \mathrm{C}$ for $2 \mathrm{~min}$, $95^{\circ} \mathrm{C}$ for $2 \mathrm{~min}$ and 35 cycles of $58^{\circ} \mathrm{C}$ for $30 \mathrm{sec}$ and $72^{\circ} \mathrm{C}$ for $40 \mathrm{sec}$. The relative expression of target genes was standardized to GAPDH, evaluated using the $2^{-\Delta \Delta \mathrm{Cq}}$ method and expressed as a ratio to control the experiments (11).

Histological analysis. The injured artery tissues from SD rats were cleared of blood with ice-cold PBS and kept in $4 \%$ paraformaldehyde for $24 \mathrm{~h}$ at $4^{\circ} \mathrm{C}$. After embedding in paraffin, sectioning to a thickness of $4 \mu \mathrm{m}$ and mounting on slides, tissues were deparaffinized and rehydrated by successive incubations in xylene, $100 \%$ ethanol, $95 \%$ ethanol, $75 \%$ ethanol, and PBS. Sections were then stained with hematoxylin and eosin using a standard protocol, or treated with rabbit anti-TMEM66 antibody (1:100, Abcam) for immunohistochemistry.

Co-immunoprecipitation. The artery tissue lysates $(400 \mu \mathrm{g}$ protein/ml supernatant) were incubated with affinity-purified anti-Orail receptor antibody ( $5 \mu \mathrm{l} / \mathrm{ml}$; cat. no. ab59330; Abcam) for $2 \mathrm{~h}$ at room temperature and protein-G agarose at $4^{\circ} \mathrm{C}$ for $12 \mathrm{~h}$. The immunoprecipitates were subjected to immunoblotting with the Stim1 antibody (1:300; cat. no. ab57834; Abcam).

Cell culture and treatment. Embryonic thoracic aortic smooth muscle A10 cells (ATCC, American Type Culture
Collection) were cultured at $37^{\circ} \mathrm{C}$ in a $95 \%$ air $/ 5 \% \mathrm{CO}_{2}$ atmosphere in DMEM/F-12. TMEMT66 transduction was performed using the lentivirus-based pLenti6.3-TMEM66 plasmid (Invitrogen Life Technologies; Thermo Fisher Scientific, Inc.). Next, the A10 cells were cultured in $3 \mathrm{ml}$ DMEM containing 3\% FBS, $10 \mu \mathrm{g} / \mathrm{ml}$ polybrene and virus (MOI=100). The medium was replaced $48 \mathrm{~h}$ after transfection, and then $5 \mu \mathrm{g} / \mathrm{ml}$ blasticidin was incubated in the medium for the next $48 \mathrm{~h}$. The cells were incubated with platelet-derived growth factor-BB (PDGF-BB $(30 \mathrm{ng} / \mathrm{ml})$ (R\&D Systems) for $24 \mathrm{~h}$.

Cell proliferation and migration assays. Cell proliferation was assessed using a 5-bromo-2'-deoxyuridine (BrdU) staining kit (BioVision, Inc.) and the Cell Counting Kit-8 assay (CCK-8; Beyotime Institute of Biotechnology), according to the manufacturer's instructions. Briefly, for BrdU staining, cells were pulsed with BrdU for $2 \mathrm{~h}$ after $24 \mathrm{~h}$ PDGF-BB stimulation. BrdU incorporation was visualized by immunocytochemical staining with the anti-BrdU monoclonal antibody (BioVision, Inc.). The cells were then fixed with $4 \%$ paraformaldehyde and stained with 4',6-diamidino-2-phenylindole (DAPI). The number of BrdU-positive cells were counted using fluorescent microscopy from three randomly chosen high power fields (magnification, x20). Cells were also seeded into 96-well plates and incubated with CCK-8 for $2 \mathrm{~h}$ at $37^{\circ} \mathrm{C}$. Absorbance was determined using a spectrophotometer (Model 680; Bio-Rad Laboratories, Inc.) at $450 \mathrm{~nm}$. Moreover, a wound scratch assay was used to determine cell migration. A10 cells were cultured in a 6 -well dish until $>90 \%$ confluent was achieved. The scratching was performed with a $200-\mu 1$ sterile pipette tip by creating a line. The cells were then incubated with PDGF-BB for $24 \mathrm{~h}$. Images were obtained by phase contrast microscopy at $\mathrm{x} 40$, and the number of migrated cells were counted under a light microscope.

Intracellular calcium measurement. Intracellular calcium was measured using a Thermo Varioskan flash instrument (Thermo Fisher Scientific, Inc.) as previously described (12) with various modifications. Briefly, A10 cells were seeded in 96-well cell culture plates together with $5 \mu \mathrm{M}$ calcium-dependent fluorescent indicator Fura-2 in DMEM at $37^{\circ} \mathrm{C}$. The cells were then washed twice with $\mathrm{Ca}^{2+}$-free Krebs buffer $(140 \mathrm{mM}$ $\mathrm{NaCl}, 5.4 \mathrm{mM} \mathrm{KCl}, 1.2 \mathrm{mM} \mathrm{MgSO}_{4}, 0.3 \mathrm{mM} \mathrm{NaH}_{2} \mathrm{PO}_{4}, 10 \mathrm{mM}$ HEPES, $5 \mathrm{mM}$ glucose, pH 7.4 with Tris base) and measured by the flash instrument with every $5 \mathrm{sec}$ alternating between 340 and $380 \mathrm{~nm}$ excitation ( $2 \mathrm{~nm}$ slit size) at $510 \mathrm{~nm}$ emission (5-nm slit size). The free $\mathrm{Ca}^{2+}$ concentration $\left[\mathrm{Ca}^{2+}\right]_{\text {free }}$ was calculated from the equation (13): $\left[\mathrm{Ca}^{2+}\right]_{\text {free }}=\mathrm{K}_{\mathrm{d}}\left[\left(\mathrm{R}-\mathrm{R}_{\min }\right) /\left(\mathrm{R}_{\max }-\mathrm{R}\right)\right]$ $\left(\mathrm{F} 380_{\max } / \mathrm{F} 380_{\min }\right)$; The $\mathrm{K}_{\mathrm{d}}$ is the dissociation constant of Fura-2 to calcium. $\mathrm{R}$ is the ratio of each $340 / 380 \mathrm{~nm}$. For the positive control, the cells were incubated with calcium channel blocker, verapamil, for $2 \mathrm{~h}$, to reduce the $\mathrm{Ca}^{2+}$ concentration. Minimum and maximum are the fluorescence values of cells treated by Triton X-100 (saturating $\mathrm{Ca}^{2+}$ concentration) or by EGTA (zero $\mathrm{Ca}^{2+}$ concentration).

Statistical analysis. Statistical analysis was performed using SPSS 22.0 software (IBM Corp.). Comparisons between two groups was carried out using dependent paired t-test, and 
A

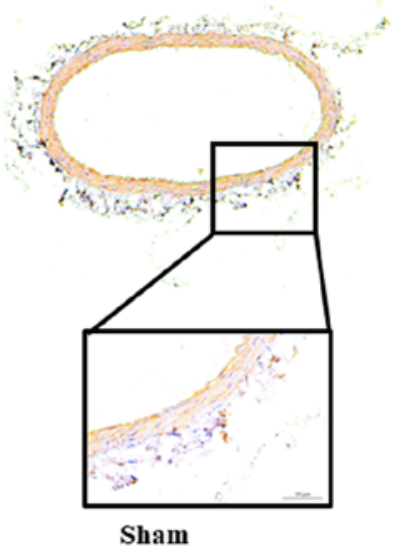

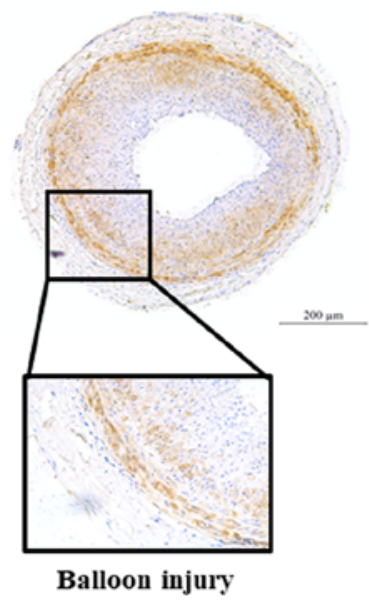

B

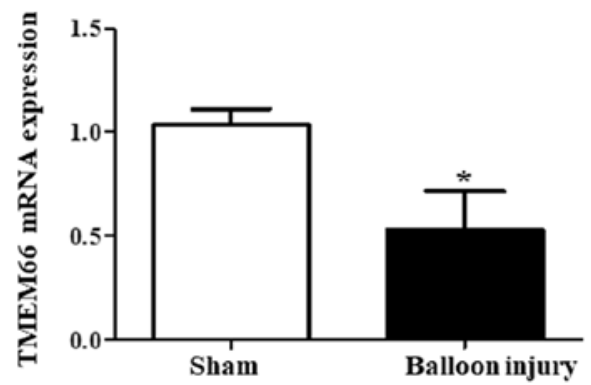

C
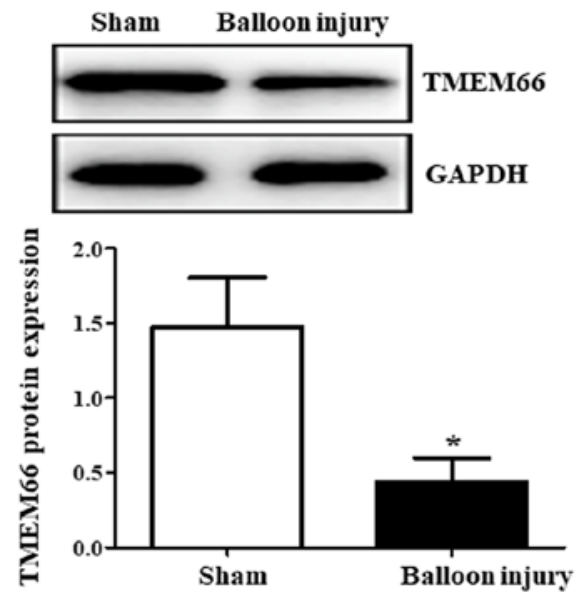

Figure 1. TMEM66 expression in carotid artery tissue after balloon injury. (A) TMEM66 distribution was determined by immunohistochemical staining. TMEM66 was found in the medial and neointimal layers of the carotid artery after balloon injury. (B) Quantitative real-time PCR was used to determine the TMEM66 mRNA expression after carotid artery injury ( $(\mathrm{P}<0.05$, vs. the sham control, $\mathrm{n}=4)$. $(\mathrm{C})$ TMEM66 protein expression was assessed by immunoblotting ( $\mathrm{P}<0.05$, vs. the sham control, $\mathrm{n}=4)$. TMEM66, transmembrane protein 66.

comparisons among more than two groups was carried out by repeated measures one-way ANOVA. Data are expressed as mean \pm SEM. A probability value $\mathrm{P}<0.05$ was considered as indicative of statistical significance.

\section{Results}

TMEM66 $m R N A$ and protein expression after carotid artery injury. We first determined the expression of TMEM66 after carotid artery injury by immunostaining, immunoblotting and qPCR. Immunostaining of the arterial sections revealed expression of TMEM66 in the medial and neointimal layers of the carotid artery after balloon injury (Fig. 1A). TMEM66 mRNA from the carotid artery tissue was significantly decreased after balloon injury (Fig. 1B). Moreover, TMEM66 protein was lower in the balloon-injured artery than that noted in the sham control (Fig. 1C), indicating that the impairment of TMEM66 expression by balloon injury occurred at both the post-translational and transcriptional levels.

TMEM66 overexpression attenuates neointimal hyperplasia. To investigate whether or not TMEM66 is involved in protection against neointimal hyperplasia, the carotid artery thickness in TMEM66-overexpression mice was determined after balloon injury. The histological analysis showed that balloon injury significantly increased the ratio of the intima to media thickness in the carotid artery, whereas the ratio of intima to media thickness was reversed in the TMEM66-overexpression mice (Fig. 2A).
Moreover, A10 cell proliferation was determined by BrdU labeling (Fig. 2B) and Cell Counting Kit-8 (CCK-8, Fig. 2C). A10 cells with TMEM66 overexpression exhibited a significant decrease in cell proliferation in response to PDGF-BB. The effect of lentivirus overexpression of TMEM66 on PDGF-BB-induced A10 cell migration was also assessed by scratch assay. It was demonstrated that TMEM66 also reduced the cell migration induced by the PDGF-BB (Fig. 2D). In addition, expression levels of $\alpha$-smooth muscle actin ( $\alpha$-SMA) and calponin were decreased following PDGF-BB treatment, while TMEM66 overexpression significantly restored these VSMC phenotypic markers at the mRNA (Fig. 3A) and protein (Fig. 3B) expression levels.

TMEM66 overexpression downregulates modulators of SOCE. Stim1 and Orai1 are critical molecules involved in the modulation of SOCE activation in VSMCs (14). Therefore, our further experiments assessed the expression of Stim1 and Orai1 in balloon injured carotid artery with or without TMEM66 transduction. The data revealed that TMEM66 overexpression reduced the increased expression of Stim1 and Orail after balloon injury (Fig. 4A). In addition, TMEM66 destabilized the SOCE signalplexes: Interaction of Stim1 and Orail was increased in the PDGF-BB-treated A10 cells, while it was deceased by TMEM66 overexpression (Fig. 4B). Due to the role of TMEM66 in SOCE modulators, the intracellular free $\left[\mathrm{Ca}^{2+}\right]$ was assessed. It was demonstrated that TMEM66 overexpression reduced the PDGF-BB treatment-enhanced $\left[\mathrm{Ca}^{2+}\right]_{\mathrm{i}}$ (Fig. 5). 


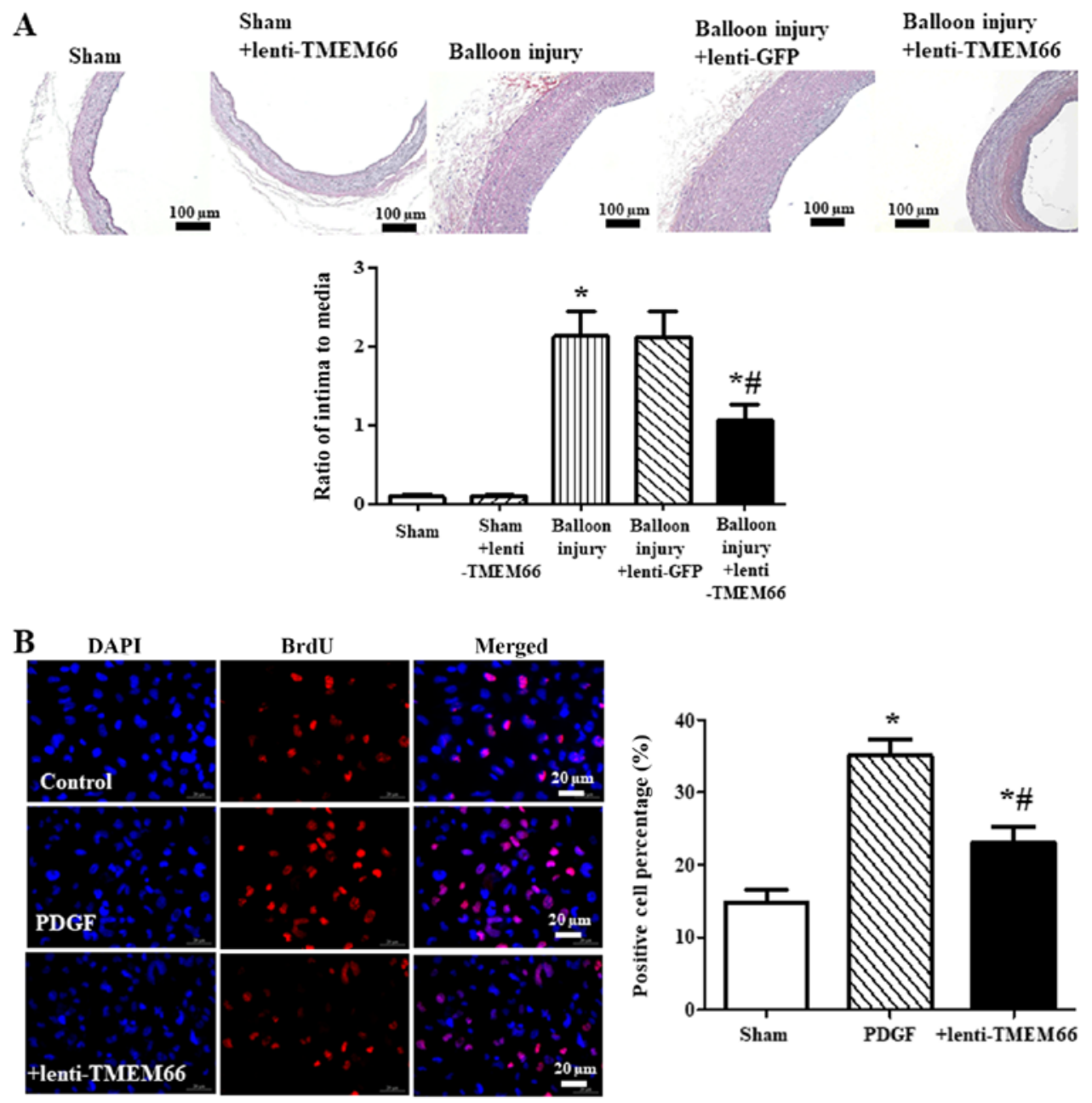

C

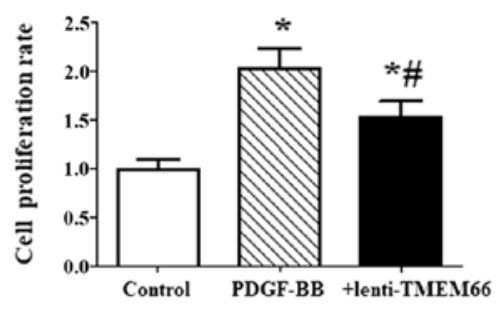

D
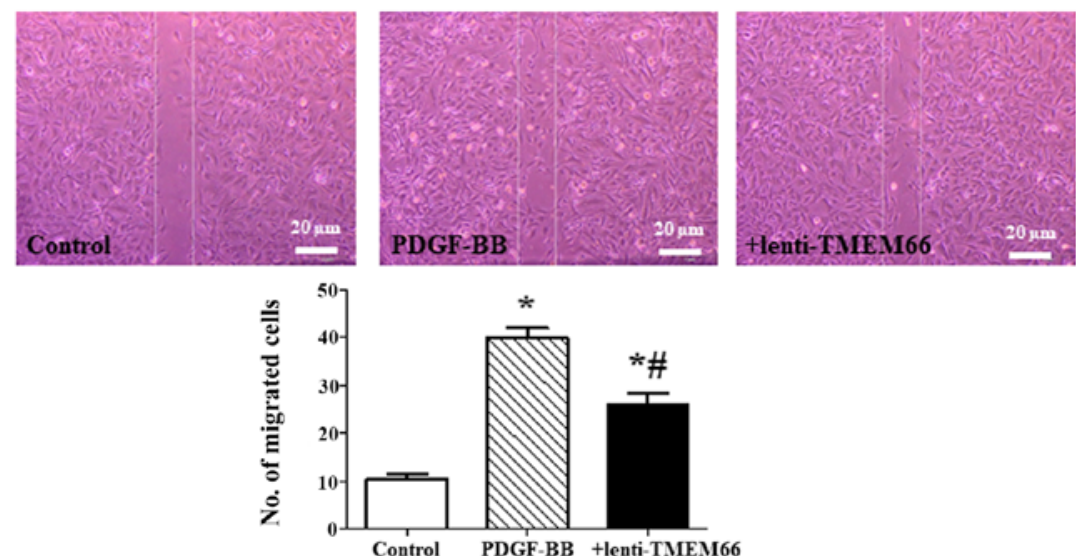

Figure 2. Effect of TMEM66 overexpression on neointimal hyperplasia. (A) Hematoxylin and eosin staining of carotid artery showed the thickness of the neointima ( $\mathrm{P}<0.05$, vs. the sham control; ${ }^{*} \mathrm{P}<0.05$, vs. the balloon injury group, $\left.\mathrm{n}=4\right)$. +lenti-TMEM66 means TMEM66 overexpression before balloon injury. Scale bar, $100 \mu \mathrm{m}$. (B and C) BrdU labeling (B) and CCK-8 assay (C) were used to determine A10 cell proliferation $\left({ }^{*} \mathrm{P}<0.05\right.$, vs. the control; ${ }^{\#} \mathrm{P}<0.05$, vs. PDGF-BB treatment, $\mathrm{n}=6$ ). +lenti-TMEM66 means TMEM66 overexpression before PDGF-BB treatment. Scale bar, $20 \mu \mathrm{m}$. (D) Migration ability was assessed by cell wound scratch assay. The number of migrated cells was counted $24 \mathrm{~h}$ after scratching $\left({ }^{*} \mathrm{P}<0.05\right.$, vs. the control; " $\mathrm{P}<0.05$ vs. PDGF-BB treatment, $\mathrm{n}=6$ ). +lenti-TMEM66 means TMEM66 overexpression before PDGF-BB treatment. Scale bar, $20 \mu \mathrm{m}$. TMEM66, transmembrane protein 66; PDGF-BB, platelet-derived growth factor-BB. 
A
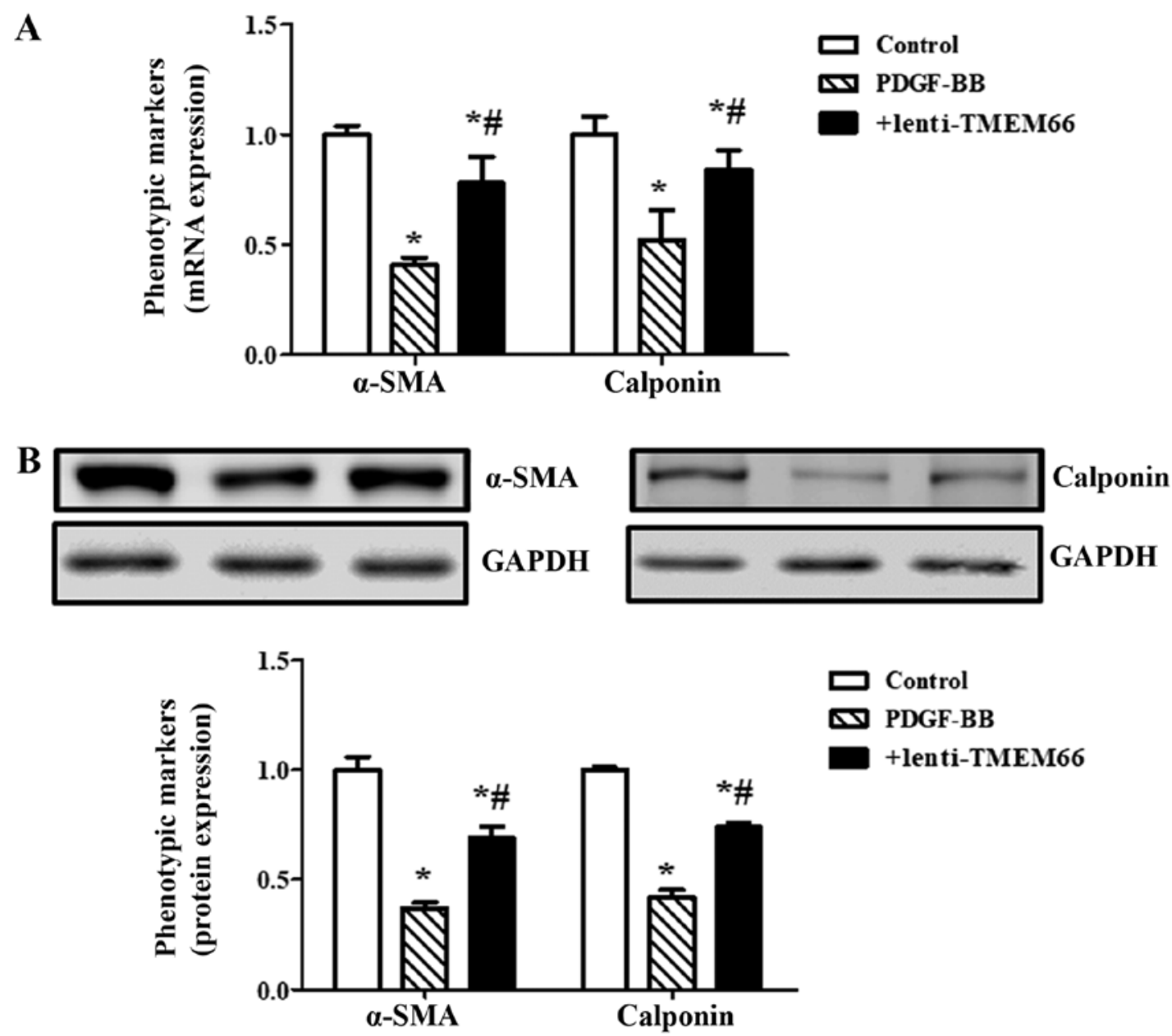

Figure 3. Effect of TMEM66 overexpression on VSMC phenotypic transformation. The mRNA (A) and protein (B) expression of VSMC phenotypic markers ( $\alpha$-SMA and calponin) was determined ("P $<0.05$, vs. the control; " $\mathrm{P}<0.05$ vs. PDGF-BB treatment, $\mathrm{n}=6$ ). +lenti-TMEM66 means the TMEM66 overexpression before PDGF-BB treatment. TMEM66, transmembrane protein 66; VSMC, vascular smooth muscle cell; $\alpha$-SMA, $\alpha$ smooth muscle actin; PDGF-BB, platelet-derived growth factor-BB.

A
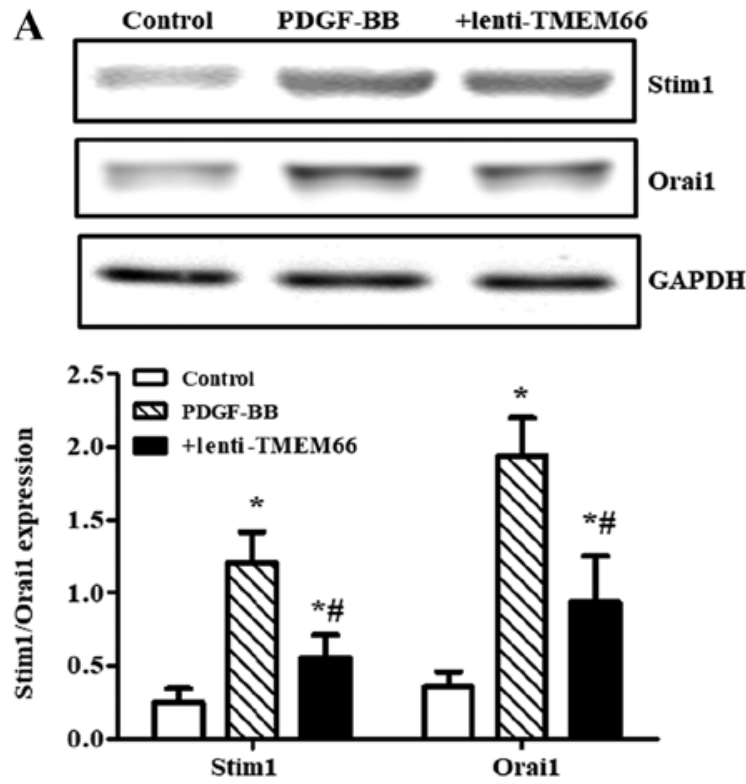

B
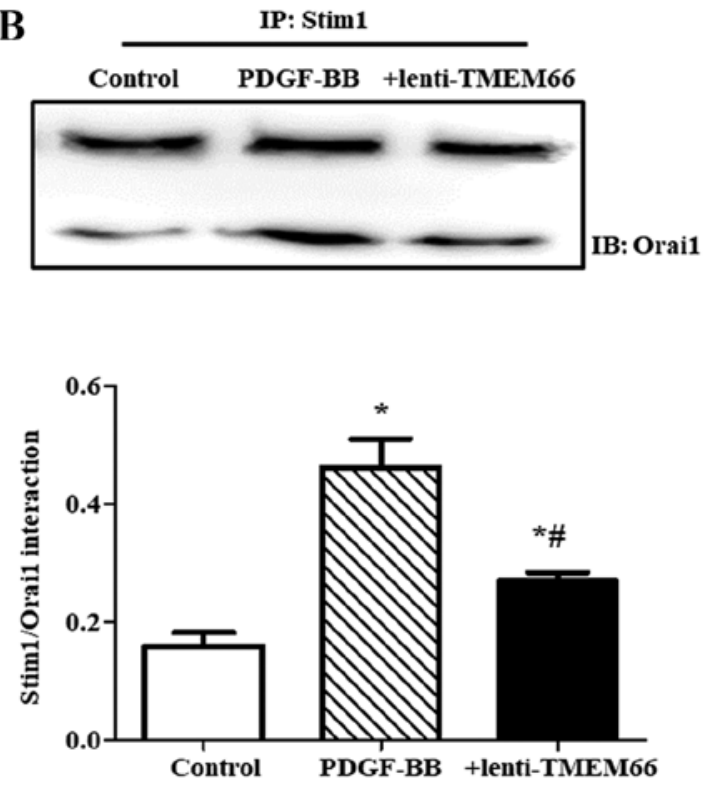

Figure 4. Stim1 and Orai1 expression and interaction. (A) Protein expression of Stim1 and Orai1 was assessed by immunoblotting ("P $<0.05$, vs. the control; ${ }^{\text {"P }}<0.05$ vs. PDGF-BB treatment, $\mathrm{n}=6$ ). +lenti-TMEM66 means the TMEM66 overexpression before PDGF-BB treatment. (B) Co-immunoprecipitation of Stim1 and Orail in PDGF-BB-treated and TMEM66-overexpressing A10 cells. The cell lysate was immunoprecipitated with Stim1 antibodies and immunoblotted with Orai1 antibodies ("P $<0.05$, vs. the control; ${ }^{*} \mathrm{P}<0.05$ vs. PDGF-BB treatment, $\mathrm{n}=6$ ). +lenti-TMEM66 means the TMEM66 overexpression before PDGF-BB treatment. TMEM66, transmembrane protein 66; PDGF-BB, platelet-derived growth factor-BB. 


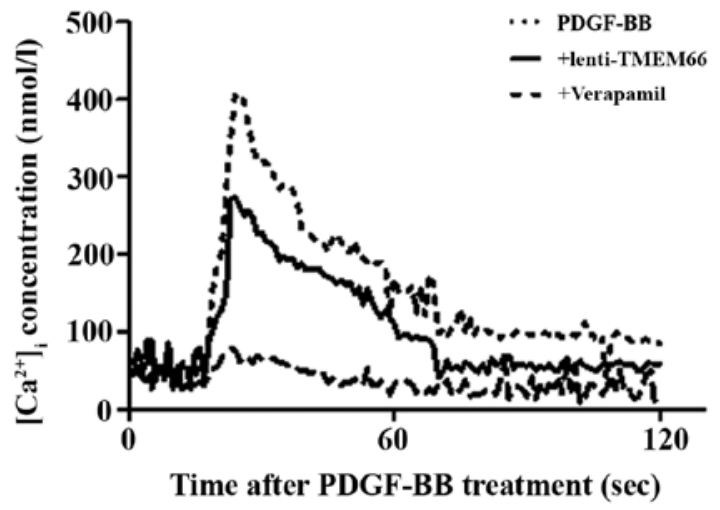

Figure 5. Intracellular calcium concentration in PDGF-BB-treated and TMEM66-overexpressing A10 cells. Representative tracing of the effect of PDGF-BB on intracellular free calcium $\left[\mathrm{Ca}^{2+}\right]_{\mathrm{i}}$ in A10 cells. PDGF-BB was added $15 \mathrm{sec}$ after the start of the experiment $(\mathrm{n}=5)$. For the positive control, the cells were incubated with calcium channel blocker, verapamil, for $2 \mathrm{~h}$, to reduce the $\mathrm{Ca}^{2+}$ concentration. TMEM66, transmembrane protein 66 ; PDGF-BB, platelet-derived growth factor-BB.

\section{Discussion}

The calcium ion, as an important secondary messenger, is a master regulatory molecule and an established signal for promoting diseases. Neointimal hyperplasia and relevant vascular smooth muscle cell (VSMC) phenotypes are dependent on $\mathrm{Ca}^{2+}(4)$, especially store operated $\mathrm{Ca}^{2+}$ entry (SOCE) (15). Transmembrane protein 66 (TMEM66), known as the store-operated $\mathrm{Ca}^{2+}$ entry-associated regulatory factor (SARAF), is a 339-amino acid protein that has been presented as a novel regulator of SOCE and modulates intracellular $\mathrm{Ca}^{2+}$ homeostasis $(6,16)$. The data presented in this study are consistent with the hypothesis that TMEM66 was expressed in the medial and neointimal layers of injured artery and the expression of TMEM66 was markedly decreased. The results revealed that TMEM66 was impaired by balloon injury at both the post-translational and transcriptional levels, and the decreased expression of TMEM66 could be a key factor in the pathological process of neointimal hyperplasia.

Due to the impairment of TMEM66 expression after balloon injury, lenti-TMEM66 plasmids were transduced into the carotid artery to induce TMEM66 protein overexpression. TMEM66 attenuated neointimal hyperplasia by suppressing the proliferation and migration of the VSMCs, which is ascribed to the inhibitory effect of TMEM66 on VSMC phenotypic changes. VSMCs have been divided into contractile and synthetic/proliferative. The proliferation and migration of proliferative VSMCs were found to be significantly increased, and contribute to the formation of neointimal hyperplasia and the development of restenosis after vascular injury $(17,18)$. In VSMCs, increased $\left[\mathrm{Ca}^{2+}\right]_{\mathrm{i}}$ initiates VSMC contraction as excitation-contraction coupling, while $\mathrm{Ca}^{2+}$, as a secondary messenger, affects gene expression as excitation-transcription coupling (19). Excessive $\mathrm{Ca}^{2+}$ influx, which has been thought as toxic $\left[\mathrm{Ca}^{2+}\right]_{\mathrm{i}}$, leads to phenotypic marker expression and phenotypic modulation in VSMCs, whereby the cells start to proliferate, migrate, and synthesize excessive extracellular matrix (20), and finally causes neointimal hyperplasia. Thus, decreasing $\left[\mathrm{Ca}^{2+}\right]_{\mathrm{i}}$ may be involved in the regulation of TMEM66 leading to VMSC proliferation and migration.

The data presented in this study are consistent with the hypothesis that TMEM66 reduces intracellular calcium concentrations. The $\mathrm{Ca}^{2+}$ concentration is determined by ion channels and pumps. Although the transient receptor potential cation channel (TRPC) family members are involved in SOCE (21), the essential components of $\mathrm{Ca}^{2+}$ release-activated $\mathrm{Ca}^{2+}$ (CRAC) channels, Stim1 and Orai1, are key $\mathrm{Ca}^{2+}$ influx channels (22) and critical molecules for SOCE activation in VSMCs (14). Stim1 is a $\mathrm{Ca}^{2+}$ sensor and detects the depletion of $\mathrm{Ca}^{2+}$ concentration in the endoplasmic reticulum by a conserved $\mathrm{Ca}^{2+}$ binding domain, which leads to Stiml oligomerization and redistribution to binding to Orail directly $(23,24)$. The interaction of Stim1 and Orail causes channel opening and $\mathrm{Ca}^{2+}$ entry $(25,26)$. In the present study, it was shown that TMEM66 overexpression reduced the increased expression of Stim1 and Orail after balloon injury. Moreover, the stabilization of Stim1-Orai1 binding was decreased by TMEM66 transduction as previously reported (6). TMEM66 responds to an elevated intracellular $\mathrm{Ca}^{2+}$ concentration and promotes an inactivation process of Stim1-mediated SOCE activity. Moreover, the destabilization effect of TMEM66 on the Stim1/Orail complex is dependent on the similar topology and overall structure with Stim1. TMEM66 also contains a serine-proline rich domain at the C-terminal tail, which may aid its interaction with plasma membrane phospholipids $(27,28)$.

In conclusion, our data indicated that TMEMT66 protects against the balloon injury-induced neointimal hyperplasia by suppressing the Stim1/Orai1 complex expression and interaction. Thus, TMEMT66 may be a pharmacological target for the treatment of neointimal hyperplasia and restenosis after percutaneous coronary intervention.

\section{Acknowledgements}

Not applicable.

\section{Funding}

The present study was supported in part by grants from the National Natural Science Foundation of China (grant nos. 81770299 and 81470396) to DY and the National Natural Science Foundation of China (grant no. 81500224) to QW.

\section{Availability of data and materials}

The datasets used and/or analyzed during the current study are available from the corresponding author on reasonable request.

\section{Authors' contributions}

JY, QW and DY conceived and designed the study. JY, SL and DY performed the experiments. SL and DY wrote the paper. QW and DY reviewed and edited the manuscript. All authors read and approved the manuscript and agree to be accountable for all aspects of the research in ensuring that the accuracy or integrity of any part of the work are appropriately investigated and resolved. 


\section{Ethics approval and consent to participate}

This study was approved by the Research Council and Animal Care and Use Committee of The General Hospital of Western Theater Command. All experiments were conformed to the guidelines of the American Association for the Accreditation of Laboratory Animal Care and conformed to the guidelines of the ethical use of animals, and all efforts were made to minimize animal suffering and to reduce the number of animals used.

\section{Patient consent for publication}

Not applicable.

\section{Competing interests}

The authors declare that they have no competing interests.

\section{References}

1. Byrne RA, Stone GW, Ormiston J and Kastrati A: Coronary balloon angioplasty, stents, and scaffolds. Lancet 390: 781-792, 2017.

2. Serruys PW, Luijten HE, Beatt KJ, Geuskens R, de Feyter PJ, van den Brand M, Reiber JH, ten Katen HJ, van Es GA and Hugenholtz PG: Incidence of restenosis after successful coronary angioplasty: A time-related phenomenon. A quantitative angiographic study in 342 consecutive patients at 1,2,3, and 4 months. Circulation 77: 361-371, 1988.

3. Shimada Y, Kataoka T, Courtney BK, Morino Y, Bonneau HN, Yock PG, Grube E, Honda Y and Fitzgerald PJ: Influence of plaque calcium on neointimal hyperplasia following bare metal and drug-eluting stent implantation. Catheter Cardiovasc Interv 67: 866-869, 2006.

4. Zhang W, Zhang X, Gonzalez-Cobos JC, Stolwijk JA Matrougui K and Trebak M: Leukotriene-C4 synthase, a critical enzyme in the activation of store-independent Orai1/Orai3 channels, is required for neointimal hyperplasia. J Biol Chem 290: 5015-5027, 2015.

5. Parekh AB and Putney JW Jr: Store-operated calcium channels. Physiol Rev 85: 757-810, 2005.

6. Palty R, Raveh A, Kaminsky I, Meller R and Reuveny E: Saraf inactivates the store operated calcium entry machinery to prevent excess calcium refilling. Cell 149: 425-438, 2012.

7. Jha A, Ahuja M, Maleth J, Moreno CM, Yuan JP, Kim MS and Muallem S: The STIM1 CTID domain determines access of SARAF to SOAR to regulate Orail channel function. J Cell Biol 202: 71-79, 2013.

8. Grassia G, Maddaluno M, Guglielmotti A, Mangano G, Biondi G, Maffia $\mathrm{P}$ and Ialenti A: The anti-inflammatory agent bindarit inhibits neointima formation in both rats and hyperlipidaemic mice. Cardiovasc Res 84: 485-493, 2009.

9. Matsumae H, Yoshida Y, Ono K, Togi K, Inoue K, Furukawa Y, Nakashima Y, Kojima Y, Nobuyoshi M, Kita T and Tanaka M: CCN1 knockdown suppresses neointimal hyperplasia in a rat artery balloon injury model. Arterioscler Thromb Vasc Biol 28: 1077-1083, 2008.
10. Romanuik TL, Wang G, Holt RA, Jones SJ, Marra MA and Sadar MD: Identification of novel androgen-responsive genes by sequencing of LongSAGE libraries. BMC Genomics 10: 476, 2009.

11. Livak KJ and Schmittgen TD: Analysis of relative gene expression data using real-time quantitative PCR and the 2(-Delta Delta C(T)) method. Methods 25: 402-408, 2001.

12. Monck JR, Reynolds EE, Thomas AP and Williamson JR: Novel kinetics of single cell $\mathrm{Ca} 2+$ transients in stimulated hepatocytes and A10 cells measured using fura- 2 and fluorescent videomicroscopy. J Biol Chem 263: 4569-4575, 1988.

13. Grynkiewicz G, Poenie M and Tsien RY: A new generation of $\mathrm{Ca} 2+$ indicators with greatly improved fluorescence properties. J Biol Chem 260: 3440-3450, 1985.

14. Guo RW, Yang LX, Li MQ, Pan XH, Liu B and Deng YL: Stim1and Orail-mediated store-operated calcium entry is critical for angiotensin II-induced vascular smooth muscle cell proliferation. Cardiovasc Res 93: 360-370, 2012.

15. Motiani RK, Stolwijk JA, Newton RL, Zhang X and Trebak M: Emerging roles of Orai3 in pathophysiology. Channels (Austin) 7: 392-401, 2013.

16. Albarran L, Regodón S, Salido GM, Lopez JJ and Rosado JA: Role of STIM1 in the surface expression of SARAF. Channels (Austin) 11: 84-88, 2017.

17. Lin G, Chow S, Lin J, Wang G, Lue TF and Lin CS: Effect of cell passage and density on protein kinase $\mathrm{G}$ expression and activation in vascular smooth muscle cells. J Cell Biochem 92: 104-112, 2004.

18. Yoshida T and Owens GK: Molecular determinants of vascular smooth muscle cell diversity. Circ Res 96: 280-291, 2005.

19. WamhoffBR,Bowles DK and Owens GK: Excitation-transcription coupling in arterial smooth muscle. Circ Res 98: 868-878, 2006.

20. Kudryavtseva O, Aalkjaer C and Matchkov VV: Vascular smooth muscle cell phenotype is defined by $\mathrm{Ca} 2+-$ dependent transcription factors. FEBS J 280: 5488-5499, 2013.

21. Eder P: Cardiac remodeling and disease: SOCE and TRPC signaling in cardiac pathology. Adv Exp Med Biol 993: 505-521, 2017.

22. Lee KP, Yuan JP, Hong JH, So I, Worley PF and Muallem S: An endoplasmic reticulum/plasma membrane junction: STIM1/Orai1/TRPCs. FEBS Lett 584: 2022-2027, 2010.

23. Stathopulos PB, Zheng L and Ikura M: Stromal interaction molecule (STIM) 1 and STIM2 calcium sensing regions exhibit distinct unfolding and oligomerization kinetics. J Biol Chem 284: 728-732, 2009.

24. Hogan PG, Lewis RS and Rao A: Molecular basis of calcium signaling in lymphocytes: STIM and ORAI. Annu Rev Immunol 28: 491-533, 2010.

25. Baba Y,Hayashi K, Fujii Y, Mizushima A, Watarai H,Wakamori M, Numaga T, Mori Y, Iino M, Hikida M and Kurosaki T: Coupling of STIM1 to store-operated Ca2+ entry through its constitutive and inducible movement in the endoplasmic reticulum. Proc Natl Acad Sci USA 103: 16704-16709, 2006.

26. Zhou Y, Meraner P, Kwon HT, Machnes D, Oh-hora M, Zimmer J, Huang Y, Stura A, Rao A and Hogan PG: STIM1 gates the store-operated calcium channel ORAI1 in vitro. Nat Struct Mol Biol 17: 112-116, 2010

27. Kiselyov K, Xu X, Mozhayeva G, Kuo T, Pessah I, Mignery G, Zhu X, Birnbaumer L and Muallem S: Functional interaction between InsP3 receptors and store-operated HtrP3 channels. Nature 396: 478-482, 1998.

28. Korzeniowski MK, Popovic MA, Szentpetery Z, Varnai P, Stojilkovic SS and Balla T: Dependence of STIM1/Orail-mediated calcium entry on plasma membrane phosphoinositides. J Biol Chem 284: 21027-21035, 2009. 